\title{
Examining the role of physical activity in reducing postcancer fatigue
}

\author{
Marieke F. M. Gielissen • Jan F. Wiborg • \\ Constans A. H. H. V. M. Verhagen • Hans Knoop • \\ Gijs Bleijenberg
}

Received: 24 March 2010 / Accepted: 27 June 2011 / Published online: 21 July 2011

(C) The Author(s) 2011. This article is published with open access at Springerlink.com

\begin{abstract}
Purpose Persistent fatigue is a long-term adverse effect experienced in about a quarter of patients cured of cancer. It was shown that cognitive behavior therapy (CBT) especially designed for postcancer fatigue is highly effective in reducing severe fatigue. However, it is unclear by what mechanism the fatigue reduction is reached. In many fatigue reduction programs, an increase in physical activity is assumed to reduce fatigue. The purpose of the present study is to determine whether the effect of CBT on fatigue is mediated by an increase in physical activity.

Methods Data of a previous randomized controlled trial on the efficacy of CBT for postcancer fatigue were reanalyzed (CBT, $n=41$; waiting list condition, $n=42$ ). Actigraphy was used to assess the level of objective physical activity. Cancer survivors were assessed prior as well as after the $\mathrm{CBT}$ and waiting list period. The mediation hypothesis was tested according to guidelines of Baron and Kenny. A nonparametric bootstrap approach was used to test statistical significance of the mediation effect.

Results Although CBT effectively reduced postcancer fatigue, no change in level of objective physical activity was
\end{abstract}

M. F. M. Gielissen ( $₫)$

Department of Medical Psychology (840),

Radboud University Nijmegen Medical Centre,

PO Box 9101, 6500 HB Nijmegen, The Netherlands

e-mail: m.gielissen@mps.umcn.nl

J. F. Wiborg $\cdot$ H. Knoop · G. Bleijenberg

Expert Centre Chronic Fatigue Nijmegen (4628),

Radboud University Nijmegen Medical Centre,

PO Box 9101, 6500 HB Nijmegen, The Netherlands

C. A. H. H. V. M. Verhagen

Department of Medical Oncology (452),

Radboud University Nijmegen Medical Centre,

PO Box 9101, 6500 HB Nijmegen, The Netherlands found. The mean mediation effect was $1.4 \%$ of the total treatment effect. This effect was not significant.

Conclusion The effect of CBT for postcancer fatigue is not mediated by a persistent increase in objective physical activity.

Keywords Fatigue $\cdot$ Postcancer fatigue $\cdot$ Activity . Exercise $\cdot$ Cancer survivors $\cdot$ Actigraphy

\section{Introduction}

Earlier diagnosis and improved treatment have resulted in an increasing number of people that have been treated successfully for cancer. Despite the fact that these persons have been cured from cancer, many cancer survivors still face distressing consequences as a result of their illness and/or treatment, like postcancer fatigue. Fatigue persists for months or years after completion of curative treatment in about a quarter of the cancer survivors [1-4], with major effects on the quality of life of these patients.

A previous RCT of our research group demonstrated that cognitive behavior therapy (CBT) especially designed for postcancer fatigue is highly effective in reducing fatigue severity in cancer survivors $[5,6]$. In clinical practice, physical exercise is seen as a promising strategy for treatment of fatigue during and after cancer treatment. Because an important element in CBT for postcancer fatigue is a physical activity program, the current study aimed to test a treatment model in which the effect of CBT on fatigue is mediated by an increase in physical activity.

The existing literature is ambiguous about the effects of activity on postcancer fatigue. In total, six systematic review studies have been conducted on the topic of exercise intervention studies in cancer patients. Three systematic reviews concluded that exercise is beneficial for individuals 
with postcancer fatigue [7-9], while three other systematic reviews did not find an effect of exercise on fatigue [10 12]. The differing results seen arise from differing methodologies. The systematic reviews of McNeely et al. and Jacobsen et al. did not evaluate intervention efficacy in the posttreatment period separately from the active treatment phase [7, 12]. Four systematic reviews were focused on numerous outcome measures and only limited studies on postcancer fatigue were evaluated [7, 9-11]; the systematic review of Schmitz et al. included also non-randomized controlled trials [11]. In conclusion, there is a need to establish the extent to which physical activity is helpful in the reduction of postcancer fatigue in cancer survivors.

In CBT for postcancer fatigue, an increase in the level of physical activity is stimulated. The fatigued cancer survivor selects a simple physical activity that can be performed every day (e.g., walking or cycling) and increases gradually and systematically the duration of this particular activity. The directive for a patient is to perform an activity twice a day, starting at a level of which is certain that symptoms do not aggravate. Mostly this is 5 to $10 \mathrm{~min}$. The activity level is increased with $1 \mathrm{~min}$ a day for each time the activity is performed and will end at a maximum of 60 min twice a day (Table 5). Illness-related cognitions are also targeted during the physical activity program. In particular, patients' preoccupation with their condition and their belief that they have little control over their symptoms are challenged. By the time patients are active $2 \mathrm{~h}$ a day, most patients will have become aware of the fact that they are capable of doing more without experiencing extreme fatigue and that they recover faster than before. Gradually, walking or cycling is now being replaced by other activities. One might choose to systematically expand mental and social activities, preparing the patient for a return to work or other personal targets.

In the present study, the data of the previous RCT on the efficacy of CBT for postcancer fatigue will be reanalyzed to determine whether the treatment effect of $\mathrm{CBT}$ on fatigue is mediated by an increase in physical activity.

\section{Methods}

Sample

Cancer survivors with severe fatigue were recruited from outpatient clinics of the Radboud University Nijmegen Medical Centre for participation in a RCT on the efficacy of CBT for postcancer fatigue. Patients were screened by their physician on clinically relevant systematic diseases (e.g., malnutrition, hemoglobin level, presence of hypothyroidism, and other physical comorbidities). If a physician was certain that the fatigue had no somatic cause, the patient was invited to participate. Patients completed curative treatment for cancer at least 1 year previously and had no evidence of disease recurrence at the time of participation. The minimum age at disease onset was 18 years; patients were no older than 65 years and had no current psychological or psychiatric treatment when participating in the study. The ethics committee of the hospital approved the study.

\section{Design and procedure}

We gave patients verbal and written information about the study and obtained informed consent before randomly assigning them to either the intervention condition (CBT) or the waiting list condition. Both conditions were assessed two times, at baseline and 6 months later. Patients in the waiting list condition were informed beforehand that, if desired, they could start therapy after the second assessment.

\section{CBT for postcancer fatigue}

In understanding postcancer fatigue, it is important to make a distinction between precipitating factors and perpetuating factors. The assumption is that cancer itself and/or cancer treatment may have triggered fatigue (precipitating factors), but that other factors are responsible for persistence of fatigue complaints (perpetuating factors). CBT is focused on six perpetuating factors of postcancer fatigue. They involve insufficient coping with the experience of cancer, a heightened fear of disease recurrence, dysfunctional fatigue-related cognitions, dysregulatory sleep-wake cycles, dysregulatory activity patterns, and insufficient social support and interactions [13].

Because of the existence of large differences within the group of fatigued cancer survivors [14], therapy was adapted to each individual. To determine the perpetuating factors for each patient, in addition to an interview, each factor is assessed with specific questionnaires (more details on these questionnaires are described in Gielissen [13]). Based on the tools' norm scores, it is determined whether the patient has a deviant or problem score. Subsequently, founded on the outcomes of the assessment instruments and the patient-therapist interview, a custom-built treatment plan is drawn up comprising only patient-relevant modules. However, for all patients, the physical activity program was part of their tailored treatment [13].

A mean of 12.5 sessions were given (SD 4.7) with a duration of $1 \mathrm{~h}$ during a 6-month period. Patients were offered a maximum of two sessions during a 6-month follow-up period.

Assessment

Patients were assessed prior as well as subsequent to the treatment and waiting list period. 


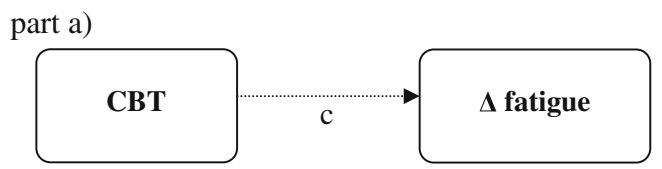

part b)

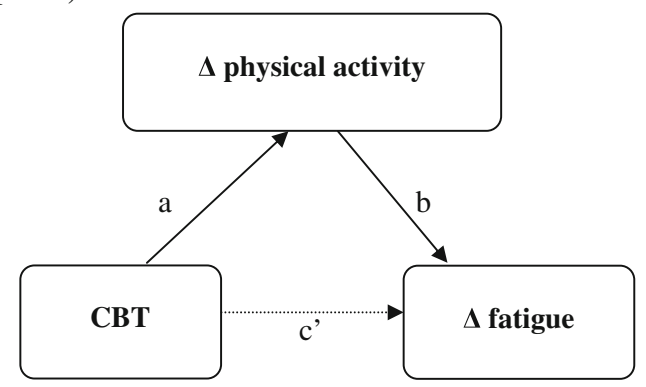

Fig. 1 The effect of CBT on postcancer fatigue without (a) and with (b) the hypothesized mediator changes in physical activity

\section{Fatigue}

The subscale fatigue severity of the Checklist Individual Strength (CIS) was used to indicate the level of fatigue experienced by patients. The subscale consists of eight items, each scored on a 7-point Likert scale (range, 8-56 points), in which the patient is asked about fatigue in the 2 weeks preceding the assessment. A score of 35 or higher indicates severe fatigue [15]. The CIS is a reliable and valid instrument $[15,16]$ and has been used for the assessment of fatigue in cancer patients $[5,17,18]$.

\section{Objective physical activity}

Actigraphy was used to measure a patient's level of objective physical activity. The actometer is a motion-sensing device developed to assess the actual level of physical activity and is worn at the ankle for 12 consecutive days prior each assessment. An average daily level of physical activity was computed over this period with higher scores indicating more physical activity. The actometer is a reliable and valid instrument [19] and has been used in cancer survivors [20]. All patients who missed actigraphy at the second assessment were excluded from the present study.
Analyses

We conducted one-way ANOVAs to test whether patients who were excluded from the present study due to missing actigraphy at the second assessment differed on baseline characteristics from those patients who were included. A chi-square test was used in case of dichotomous dependent variables. In addition, one-way ANOVAs were used to compare the CBT and waiting list condition on baseline, second assessment, and change scores concerning fatigue severity and physical activity.

Testing mediation is a strategy to identify variables which intervene in the relationship between treatment and outcome [21]. In the current study, we want to determine whether the treatment effect of CBT on fatigue is mediated by an increase in physical activity. The mediation hypothesis is depicted in Fig. 1. In Fig. 1a, a change in fatigue is simply explained by receiving CBT (path c). This model is usually tested when the efficacy of an intervention is of primary interest to the investigator. In Fig. 1b, the effect of CBT on fatigue (path $c^{\prime}$ ) is mediated by an increase in physical activity (path a) which is responsible for the reduction in fatigue (path b). A macro expansion for SPSS introduced by Preacher and Hayes [22] was used to test this mediation hypothesis. The macro consisted of a syntax file which enabled SPSS to examine the mediation hypothesis according to guidelines of Baron and Kenny [23]. Paths a, b, c, and $\mathrm{c}^{\prime}$ of Fig. 1 were analyzed using regression analysis. To examine path a, changes in physical activity were regressed on treatment. Path $b$ was examined by regressing changes in fatigue on changes in physical activity. In the case of path $\mathrm{c}$, changes in fatigue were regressed on treatment, while path $c^{\prime}$ was examined by regressing changes in fatigue on treatment, this time correcting for the mediator changes in physical activity. The size of the mediation effect was computed by multiplying path a with path $b$.

The statistical significance of the mediation effect was tested according to a non-parametric bootstrap approach [22]. In this approach, population parameters are generated empirically instead of relying on normal theory. This procedure leads to more power to detect significant differences even in small, non-normally distributed samples. The
Table 1 Baseline characteristics of included versus excluded cancer survivors

$C B T$ cognitive behavior therapy

\begin{tabular}{lccc}
\hline & Included $(n=83)$ & Excluded $(n=15)$ & $p$ value \\
\hline$n(\mathrm{CBT})$ & 41 & 9 & \\
Physical activity & $67.2(20.5)$ & $76.9(23.0)$ & 0.109 \\
Fatigue severity & $47.6(6.7)$ & $46.5(6.5)$ & 0.541 \\
Time since cancer treatment & $5.1(3.9)$ & $4.8(3.9)$ & 0.759 \\
$\%$ Female & $47 \%$ & $49 \%$ & 0.846 \\
Age & $47.4(9.0)$ & $44.5(10.2)$ & 0.306 \\
\hline
\end{tabular}


Table 2 Mean baseline, second assessment, and change score (SD) on fatigue severity and physical activity
$C B T$ cognitive behavior therapy, $S D$ standard deviation

\begin{tabular}{lccc}
\hline & CBT $(n=41)$ & Waiting list $(n=42)$ & $p$ value \\
\hline Physical activity & & & \\
Baseline & $69.3(22.5)$ & $65.2(18.3)$ & 0.364 \\
Second assessment & $73.1(21.9)$ & $65.1(24.5)$ & 0.121 \\
Change score & $3.85(26.0)$ & $-0.05(22.6)$ & 0.468 \\
Fatigue severity & & & \\
Baseline & $47.8(6.6)$ & $47.4(6.8)$ & 0.800 \\
Second assessment & $27.6(14.6)$ & $42.5(8.4)$ & 0.000 \\
Change score & $-20.2(12.9)$ & $-4.9(7.5)$ & 0.000 \\
\hline
\end{tabular}

observed dataset was randomly resampled in 5,000 samples with mediation effect. The mean of this mediation effect was used as a population parameter. The null hypothesis was rejected when the $95 \%$ confidence interval (CI) did not include zero.

All change scores were computed by subtracting second from baseline assessment. A negative change score indicated a decrease while a positive one indicated an increase on the respective variable. Threshold for significance was set at $p<0.05$.

\section{Results}

One hundred forty-five patients met the eligibility criteria, and 33 refused to take part $(23 \%)$. There were no differences on baseline characteristics between participants and nonparticipants (data not shown). Fifty-six patients were allocated to both conditions. After random assignment, 14 ineligible patients were excluded from the trial, resulting in 50 patients participating in the CBT condition and 48 in the waiting list control condition. Due to missing actigraphy at the second assessment, nine patients in the CBT condition and six in the waiting list condition could not be used in the mediation analyses. Patients excluded $(n=15)$ did not differ significantly on their baseline characteristics from included patients $(n=83$; Table 1$)$. Of the in total 83 cancer survivors, $51 \%$ were male. The mean age of the participants was $44.5(\mathrm{SD}=10.2)$. The mean duration of cancer treatment was 6.8 months $(\mathrm{SD}=6.6)$, and the treatment finished 5.1 years ago $(\mathrm{SD}=3.9)$. Thirty-one percent was treated for breast cancer, $25 \%$ for testicular cancer, $17 \%$ for hematological cancer, and $27 \%$ for other solid tumors.

In Table 2, baseline, second assessment, and change scores on physical activity (actometer) and fatigue severity (CIS-fatigue) are demonstrated for the included patients in the CBT and waiting list condition. Patients in the intervention condition reported the same level of physical activity, but a significantly greater decrease in fatigue severity, 6 months after baseline assessment, compared to patients in the waiting list condition.
Regression analyses testing the hypothesized mediating effect are seen in Table 3. Fatigue was reduced significantly more in the CBT condition than in the control group (path c). However, CBT did not produce a significant change in physical activity (path a). There was also no significant relationship between changes in physical activity and changes in fatigue (path b). The effect of treatment remained significant when it was controlled for changes in physical activity (path $\mathrm{c}^{\prime}$ ).

In Table 4, the statistical significance of the mediation was tested according to the bootstrap approach. The mean mediation effect was $1.4 \%$ of the total treatment effect. The 95\% CI of the mean mediation effect included zero. The mediation hypothesis could not be confirmed.

\section{Discussion}

The results indicated that the positive effect of CBT on postcancer fatigue was not mediated by an increase in objective physical activity measured with the actometer. CBT did not cause an increase in physical activity at the end of treatment (path a) nor was an increase in physical activity associated with a reduction in fatigue (path b). The finding that there was no effect of the interventions on physical activity already showed that mediation was absent, but as mediation analyses require a large power, a bootstrap analysis was performed. The formal test of the mediation effect confirmed that CBT yielded its effect independent of a change in physical activity. These results are in line with

Table 3 Testing path a, b, c, and $\mathrm{c}^{\prime}$ as depicted in Table 5 and Fig. 1

\begin{tabular}{lrrrr}
\hline$n=83$ & \multicolumn{1}{l}{$B$} & SE & $t$ value & $p$ value \\
\hline Path a & 3.90 & 5.34 & 0.73 & 0.468 \\
Path b & -0.05 & 0.05 & -1.02 & 0.310 \\
Path c & -15.33 & 2.30 & -6.64 & 0.000 \\
Path c' & -15.15 & 2.31 & -6.54 & 0.000 \\
\hline
\end{tabular}

SE Standard error 
Table 4 Testing the mediation effect according to the bootstrap approach

\begin{tabular}{lc}
\hline & Bootstrap \\
\hline Mediation effect & -0.21 \\
Lower CI $(95 \%)$ & -1.46 \\
Upper CI $(95 \%)$ & 0.57 \\
$\%$ total treatment effect & 1.4 \\
\hline
\end{tabular}

Wiborg et al. [24], who demonstrated that the effect of CBT on fatigue in patients with chronic fatigue syndrome was also not mediated by an increase in physical activity following treatment.

There are several potential alternative explanations for the fact that we did not find support for our mediation hypothesis. One reason could be that the actometer was not obtained from all participants, and it is possible that we introduced a bias through exclusion. Also, by excluding patients, the sample size became smaller. However, no difference on baseline characteristics was found between completers and non-completers, and the effect of CBT was still significant in the smaller group. Additionally, the bootstrap approach is sensitive to detect differences in small samples.

Gradual increase of physical activity is an important part of the treatment protocol; however, no increase was found assessed with actigraphy at the end of treatment. Our study is limited by not documenting the level of physical activity during therapy. Therefore, we do not know whether the patients became temporarily physically more active during CBT. One might assume that this is probable, as they discussed repeatedly their gradual increase in activity with the therapist as demonstrated in Table 5. Anyway, a possible temporary increase was no longer present when the second assessment took place [13].

CBT might have resulted in a temporary increase in physical activity. This temporary increase in physical activity during therapy might have been sufficient to facilitate a persistent change in illness-related cognitions and reduce fatigue. The gradual increase of physical activity can help the patient to feel (more) confident that he or she is actually capable of achieving these activities despite his or her symptoms, thereby enhancing his or her sense of control and bringing about a positive self-efficacy. This would be an interesting hypothesis to explore in future research.

In addition, CBT for postcancer fatigue is also focused on five other perpetuating factors of severe fatigue. It seems logical to assume that the positive effect of CBT on postcancer fatigue was mediated by change in the other perpetuating factors. Future research should therefore be focused on examining the exact mechanisms of change in CBT by monitoring illness-related cognitions and physical activity repeatedly during therapy and on determining the exact role of each perpetuating factor.

The association between fatigue and depression is complex. Fatigue can occur as a symptom of depression or may precipitate feelings of depression because of its interference with mood, work, and leisure activities. However, it is

Table 5 Example of a patient who starts two times a day to walk (or cycle) for $15 \mathrm{~min}$ and increases gradually and systematically this lowmoderate activity (one rest day during the week)

\begin{tabular}{|c|c|c|c|c|c|c|c|c|c|c|c|c|c|c|c|c|c|c|c|c|}
\hline Min & & & & & & & & & & & & & & & & & & Cor & nues - & \\
\hline \multicolumn{21}{|l|}{29} \\
\hline 28 & & & & & & & & & & & & & & & & & & & $x x$ & $x$ \\
\hline 27 & & & & & & & & & & & & & & & & & $\mathrm{xx}$ & $\mathrm{xx}$ & $\mathrm{xx}$ & $\mathrm{xx}$ \\
\hline 26 & & & & & & & & & & & & & & & & $\mathrm{xx}$ & $\mathrm{xx}$ & $x x$ & $x x$ & \\
\hline 25 & & & & & & & & & & & & & & & $\mathrm{xx}$ & $\mathrm{xx}$ & $\mathrm{xx}$ & $x x$ & $x x$ & \\
\hline 24 & & & & & & & & & & & & & $\mathrm{xx}$ & & $\mathrm{xx}$ & $\mathrm{xx}$ & $\mathrm{xx}$ & $x x$ & $x x$ & $\mathrm{xx}$ \\
\hline 23 & & & & & & & & & & & & $x x$ & $\mathrm{Xx}$ & & $x x$ & $\mathrm{xx}$ & $\mathrm{xx}$ & $\mathrm{xx}$ & $x x$ & $\mathrm{xx}$ \\
\hline 22 & & & & & & & & & & $x x$ & $x x$ & $x x$ & $x x$ & & $x x$ & $\mathrm{xx}$ & $\mathrm{xx}$ & $\mathrm{xx}$ & $x x$ & \\
\hline 21 & & & & & & & & & $\mathrm{xx}$ & $x x$ & $x x$ & $x x$ & $\mathrm{xx}$ & & $x x$ & $\mathrm{xx}$ & $\mathrm{xx}$ & $\mathrm{xx}$ & $x x$ & $\mathrm{xx}$ \\
\hline 20 & & & & & & & & $x x$ & $\mathrm{xx}$ & $x x$ & $\mathrm{xx}$ & $x x$ & $\mathrm{xx}$ & & $x x$ & $\mathrm{xx}$ & $\mathrm{xx}$ & $\mathrm{xx}$ & $\mathrm{xx}$ & $\mathrm{xx}$ \\
\hline 19 & & & & & & $x x$ & & $x x$ & $x x$ & $x x$ & $x x$ & $\mathrm{xx}$ & $\mathrm{xx}$ & & $\mathrm{xx}$ & $\mathrm{xx}$ & $\mathrm{xx}$ & $\mathrm{xx}$ & $\mathrm{xx}$ & $\mathrm{xx}$ \\
\hline 18 & & & & & $x x$ & $\mathrm{xx}$ & & $\mathrm{xx}$ & $\mathrm{xx}$ & $\mathrm{xx}$ & $\mathrm{xx}$ & $\mathrm{xx}$ & $\mathrm{xx}$ & & $\mathrm{xx}$ & $\mathrm{xx}$ & $\mathrm{xx}$ & $\mathrm{xx}$ & $\mathrm{xx}$ & $\mathrm{xx}$ \\
\hline 17 & & & $x x$ & $\mathrm{xx}$ & $x x$ & $x x$ & & $\mathrm{xx}$ & $\mathrm{xx}$ & $\mathrm{xx}$ & $\mathrm{xx}$ & $\mathrm{xx}$ & $\mathrm{xx}$ & & $\mathrm{xx}$ & $\mathrm{xx}$ & $\mathrm{xx}$ & $\mathrm{xx}$ & $\mathrm{xx}$ & $\mathrm{xx}$ \\
\hline 16 & & $x x$ & $x x$ & $\mathrm{xx}$ & $x x$ & $x x$ & & $x x$ & $\mathrm{xx}$ & $\mathrm{xx}$ & $x x$ & $x x$ & $\mathrm{xx}$ & & $\mathrm{xx}$ & $x x$ & $\mathrm{xx}$ & $x x$ & $\mathrm{xx}$ & $\mathrm{xx}$ \\
\hline 15 & $x x$ & $\mathrm{xx}$ & $x x$ & $\mathrm{xx}$ & $\mathrm{xx}$ & $x x$ & & $\mathrm{xx}$ & $\mathrm{xx}$ & $\mathrm{xx}$ & $x x$ & $x x$ & $x x$ & & $x x$ & $\mathrm{xx}$ & $\mathrm{xx}$ & $x x$ & $x x$ & $\mathrm{xx}$ \\
\hline Day & 1 & 2 & 3 & 4 & 5 & 6 & 7 & 8 & 9 & 10 & 11 & 12 & 13 & 14 & 15 & 16 & 17 & 18 & 19 & 20 \\
\hline
\end{tabular}


important to realize that in most patients, postcancer fatigue occurs independently from depression [25-27].

The current study sample does not reflect the incidence and types of cancer in the Dutch population, and the sample is quite young compared to the general oncological population. Therefore, a positive effect of physical activity on fatigue cannot be ruled out, and replication is necessary in survivors matching the general oncological population.

In the literature, there is a lack of consistent evidence whether a physical activity program reduces postcancer fatigue [7-12]. Because in the current study we did not find an increase in physical activity, it remains unclear if there is a positive effect of an increase in physical activity for reducing postcancer fatigue.

However, even without an increase in physical activity, CBT was highly effective in reducing postcancer fatigue. Therefore, a persistent increase in physical activity seems not to be a requirement in reducing postcancer fatigue, and a change in illness-related cognitions is likely to play a more crucial role in CBT for postcancer fatigue.

Statement The current study is based on a previous RCT (Current Controlled Trials: ISRCTN: 44562532, Grant Dutch Cancer Society) investigating the efficacy of CBT especially designed for postcancer fatigue. This RCT was approved by the ethics committee of the hospital.

Conflict of interest The authors have no financial relationship with the organization that sponsored the research. The authors have full control of all primary data and agree to allow the journal to review the data if requested.

Open Access This article is distributed under the terms of the Creative Commons Attribution Noncommercial License which permits any noncommercial use, distribution, and reproduction in any medium, provided the original author(s) and source are credited.

\section{References}

1. Servaes P, Verhagen S, Schreuder B, Veth R, Bleijenberg G (2003) Fatigue after treatment for malignant and benign bone and soft tissue tumors. J Pain Symp Manag 26:1113-1122

2. Hjermstad SD, Fosså SD, Oldervoll L, Holte H, Jacobsen AB, Loge JH (2005) Fatigue in long-term Hodgkin's Disease survivors: a follow-up study. J Clin Oncol 23:6587-6595

3. Bower JE, Ganz PA, Desmond KA et al (2006) Fatigue in long-term breast carcinoma survivors. A longitudinal investigation. Cancer 106:751-758

4. Servaes P, Gielissen MFM, Verhagen C, Bleijenberg G (2007) The course of severe fatigue in disease-free breast cancer patients: a longitudinal study. Pycho-Oncol 16:787-795

5. Gielissen MFM, Verhagen S, Witjes JA, Bleijenberg G (2006) The effects of cognitive behaviour therapy in severely fatigued disease-free cancer patients compared to patients waiting for cognitive behaviour therapy. A randomised control trial. J Clin Oncol 24:4882-4887

6. Gielissen MFM, Verhagen S, Bleijenberg G (2007) Cognitive behaviour therapy for fatigued cancer survivors: long term followup. Brit J Cancer 97:612-618

7. McNeely M, Campbell KL, Rowe BH, Klassen TP, Mackey JR, Courneya KS (2006) Effects of exercise on breast cancer patients and survivors: a systematic review and meta-analysis. Can Med Assoc J 175:34-41

8. Cramp F, Daniel J (2008) Exercise for the management of cancerrelated fatigue in adults (review). Cochrane DB Syst Rev 2

9. Speck MS, Courneya KS, Masse LC, Duval S, Schmitz H (2010) An update of controlled physical activity trials in cancer survivors: a systematic review and meta-analysis. J Cancer Surviv 4:87-100

10. Galvao DA, Newton RU (2005) Review of exercise intervention studies in cancer patients. J Clin Oncol 23:899-909

11. Schmitz KH, Holtzman J, Courneya KS, Masse LC, Duval S, Kane R (2005) Controlled physical activity trials in cancer survivors: a systematic review and meta-analysis. Cancer Epidem Biomar Prev 14:1588-1595

12. Jacobsen PB, Donovan KA, Vadaparampil ST, Small BJ (2007) Systematic review and meta-analysis of psychological and activity-based interventions for cancer related fatigue. Health Psychol 26:660-667

13. Gielissen MFM (2007) Fatigue in cancer survivors. From assessment to cognitive behaviour therapy. Dissertation, Radboud University Nijmegen, the Netherlands http://repository.ubn.ru.nl/ bitstream/2066/45169/1/45169_fatiincas.pdf. Accessed 17 Jan 2008, Chapter 3: Cognitive behavior therapy for postcancer fatigue: a treatment protocol

14. Servaes P, Prins J, Verhagen S et al (2002) Fatigue after breast cancer and in chronic fatigue syndrome: similarities and differences. J Psychosom Res 52:453-459

15. Vercoulen JH, Swanink CM, Fennis JF, Galama JM, van der Meer JW, Bleijenberg G (1994) Dimensional assessment of chronic fatigue syndrome. J Psychosom Res 38:383-392

16. Dittner AJ, Wessely SC, Brown RG (2004) The assessment of fatigue: a practical guide for clinicians and researchers. J Psychosom Res 56:157-170

17. Servaes P, Verhagen S, Bleijenberg G (2002) Determinants of chronic fatigue in disease-free breast cancer patients, a crosssectional study. Ann Oncol 13:589-598

18. Goedendorp MM, Gielissen MFM, Verhagen S, Peters M, Bleijenberg G (2008) Severe fatigue and related factors in cancer patients before the initiation of treatment. Br J Cancer 99:14081414

19. van der Werf SP, Prins JB, Vercoulen JH, van der Meer JW, Bleijenberg G (2000) Identifying physical activity patterns in chronic fatigue syndrome using actigraphic assessment. J Psychosom Res 45:507-517

20. Servaes P, Verhagen S, Bleijenberg G (2002) Relations between fatigue, neuropsychological functioning and physical activity after treatment for breast carcinoma. Cancer 95:20172026

21. Frazier PA, Tix AP, Barron KE (2004) Testing moderator and mediator effects in counseling psychology research. J Counsel Psychol 51:115-134

22. Preacher KJ, Hayes AF (2004) SPSS and SAS procedures for estimating indirect effects in simple mediation models. Behav Res Meth Ins C 36:717-731

23. Baron RM, Kenny DA (1986) The moderator-mediator variable distinction in social psychological research: conceptual, strategic, and statistical considerations. J Pers Soc Psychol 51:11731182 
24. Wiborg JF, Knoop H, Stulemeijer M, Prins JB, Bleijenberg G (2010) How does cognitive behaviour therapy reduce fatigue in patients with chronic fatigue syndrome? The role of physical activity. Psychol Med 40:1281-1287

25. Servaes P, Verhagen C, Bleijenberg G (2002) Fatigue in cancer patients during and after treatment: prevalence, correlates and interventions. Eur J Cancer 38:27-43
26. Prue G, Rankin J, Allen J, Gracey J, Cramp F (2006) Cancer related fatigue: a critical appraisal. Eur J Cancer 42(7):846-863

27. Sugawara Y, Akechi T, Okuyama T, Matsuoka Y, Nakao T, Inagaki $\mathrm{M}$, Imoto $\mathrm{S}$, Fujimoni $\mathrm{M}$, Hosaka $\mathrm{T}$, Uchitomi $\mathrm{Y}$ (2005) Occurrence of fatigue and associated factors in diseasefree cancer patients without depression. Support Care Cancer 13(8):628-636 